\title{
The predictive role of forgiveness and the level of repetitive thinking on mental health and marital adjustment in married individuals
}

\author{
Isil Goztepe Gumus ${ }^{1 \oplus}$, Sennur Tutarel Kislak ${ }^{\circledR}$ \\ 'Ozel Koru Ankara Hospital, Department of Psychology, Ankara - Turkey \\ ${ }^{2}$ Ankara University, Department of Psychology, Ankara - Turkey
}

\begin{abstract}
Objective: A review of the literature reveals that while forgiveness, the importance attached to negative experiences to be forgiven, and repetitive thinking are associated with marital adjustment, the role of variables regarding close relationships has so far received little attention from researchers. As the marital relationship, one of the most important interpersonal relations, correlates to mental health, this study aims to examine jointly the predictive power of relevant variables for psychological symptoms and marital adjustment and additionally to investigate possible gender differences in terms of these research variables.

Method: The sample of this study consisted of 157 married individuals (86 women and 71 men). Marital Adjustment Test (MAT), Brief Symptom Inventory (BSI), Forgiving Personality Scale (FP), Repetitive Thinking Questionnaire (RTQ), Importance Attached to the Incident to be Forgiven Scale (IAIFF), and a Personal Information Form developed by the researchers were administered to married persons. Correlation analysis was conducted to examine the relations between variables; subsequently, hierarchical regression analysis was applied to determine the power of the variables to predict psychological symptoms and marital adjustment. One-way MANOVA was used to reveal gender differences with regard to the research variables.

Results: Regression analysis showed that gender, repetitive thinking, forgiving personality, and the importance given to negative experiences expected to be forgiven predict psychological symptoms. In addition, gender, forgiving personality, and repetitive thinking have a significant predictive value for marital adjustment. Finally, gender differences were found to be significant in marital adjustment, psychological symptoms, repetitive thinking, and the importance attached to negative experiences to be forgiven. It was determined that marital adjustment was lower in women while their psychological symptoms were higher.

Conclusion: This study demonstrates that repetitive thinking and forgiveness are important predictor variables for both mental health and marital adjustment. It also suggests that marital therapists should consider relevant variables in psychotherapy when working with married couples.
\end{abstract}

Keywords: Forgiveness, marital adjustment, psychological symptoms, repetitive thinking, rumination.

\section{INTRODUCTION}

The family is the smallest unit of society in which its members live their biological, psychological, and social relations and emotional interactions. While the family as an institution has undergone a number of changes in size and composition in the historical process, it retains its characteristic as a basic unit of society in every

How to cite this article: Goztepe Gumus I, Tutarel Kislak S. The predictive role of forgiveness and the level of repetitive thinking on mental health and marital adjustment in married individuals. Dusunen Adam The Journal of Psychiatry and Neurological Sciences 2019;32:236-245.

Correspondence: İsil Goztepe Gumus, Ozel Koru Ankara Hospital, Department of Psychology, Ankara - Turkey

Phone: +90 5301707111 E-mail: isilgoztepe@gmail.com

Received: July 23, 2018; Revised: August 27, 2018; Accepted: April 15, 2019 
culture (1). From the perspective of approaches that consider the family a whole of systems, the family is a continuous, living structure consisting of individuals in a web of interactions related with one another, having responsibilities. To be emphasized as a subsystem within the family system is the spousal dyad consisting of wife and husband in the marital relationship $(1,2)$. Marriage is a social system in official, emotional, behavioral, and biological ways (3). In general, marriage is evaluated under two aspects. The first concept is the "duration of marriage" and includes issues such as divorce, separation, or leaving, while the second is "marital quality," which is related with questions such as how the marital relationship develops during marriage, how the spouses feel about it and how the quality of marriage affects the partners. In the evaluation of marital quality, adjustment is considered to be an important concept, and therefore in many studies about marriage we often find approaches regarding factors affecting adjustment and its development $(4,5)$. Marital adjustment is a measure for the degree to which desires, expectations, and needs are met in marriage (6), and furthermore, it refers to a balance between the necessary and voluntary aspects of marriage (3).

Studies on adjustment problems experienced in married life have focused on how individuals solved these problems, how they expressed their feelings towards the other, or on the emotion, sentiment, and behaviors that each partner brought to the relationship as a factor of continuity (7). There are a number of areas that may create difficulties in marriage, including a lack of empathetic understanding, a continuation of inadequate ways of communication, problems experienced in the sexual relation, an inconsistency in female and male roles, changes in family income and unemployment, having a disabled child or being unable to have children, lacking behavioral openness and sincerity, extramarital affairs, spouses' cultural change and inability to keep up with their development, children leaving home, and spouses approaching old age (1).

A well-adjusted marriage plays an important role in human life and is relevant for individuals' psychological health (8). Persons experiencing incompatibility and conflict in their marriage often suffer from psychological disorders and seek psychological help (3). In sum, for happiness, stability, and harmony, individually as well as in the marital relationship, it is important how the spouses deal with adverse experiences.

In the psychological literature, an increasing number of studies demonstrate the positive correlation of forgiveness with mental health in interpersonal relations (9), and its importance in marital relationships is gaining greater importance (10). Forgiveness is defined as a person, having been offended by someone else, consciously leaving behind these negative experiences (11). There are findings indicating that forgiveness as a personality trait is positively related with positive affect, satisfaction with life, and optimism (12) and negatively related with negative affect (13-15). It has been emphasized that the positive effects of forgiveness for the individual encompassed physical and mental health and satisfaction with life (9), contributing positively to the marital relationship; and more forgiving couples were happier in their relationship and less inclined to display a negative attitude towards each other (10). In the Process Model of Forgiveness, this phenomenon is approached as a complex, step-by-step process (16). The Hargrave Forgiveness Model assesses forgiveness as an important factor in overcoming resentments and reestablishing lost trust in close relationships (17). The Social-Psychological Determinants Model of Forgiveness approaches forgiveness as a motivational social-psychological factor consisting of motivational and positive social behaviors. In addition, this model emphasizes rumination as one of the factors directly affecting the forgiveness process in interpersonal relations (18).

In the response style model, rumination, considered a kind of repetitive thinking, is defined as a person's repeatedly thinking about a problem and the related mood without taking any action rather than actively trying to solve the existing problem. This model asserts that rumination increases negative thought and causes a decline in problem-solving skills, instrumental behaviors, and social support, which may explain the tendency of individuals to develop psychological problems accordingly (19). It is said that like forgiveness, rumination might significantly affect mental health, create a cognitive disposition for depression (19-22), and lay the ground for the development of mood disorders $(20,23)$. It has been indicated that growing negative thought content increases psychological symptoms while positive thought content contributes to psychological and physical health (24). The literature accepts the existence of a positive correlation between rumination and depression $(19,20,25,26)$, while the possibility of rumination being related with other psychopathologies is also being discussed. For example, there are indications for rumination to be correlated with anger, hostility, anxiety (15), alcohol abuse (27), self-harming behaviors (28), or eating disorders (29). 
While the marital relation is one of the most important interpersonal relations, inevitably it occasionally creates dynamics causing the partners strain or harm. For happiness and stability of the partners and the marital relationship, it is important how negative experiences are being dealt with. In this context, it seems that the concept of forgiveness plays an important role in the marital relation requiring scientific study. In the area of close relationships, the concept of forgiveness is relatively new, and knowledge relating to this field is not sufficiently broad. In close relationships, forgiveness after an offending experience allows to erase the traces of this experience (30), reduce conflict in the relationship, display more positive behavior, and improve the couple's cognition (10). Some studies in the literature describe forgiveness as one of the cornerstones of marital success, stating, for example, that forgiveness correlates positively with marital satisfaction $(10,31)$ or predicts the quality of marriage $(32,33)$. Relevant studies propose that forgiveness facilitates the solution of current or future problems and contributes positively to the marital relationship. However, when looking at the literature more broadly, it appears that studies examining the role of forgiveness in marital relationships are not yet sufficient and the range of variables being evaluated needs to be broadened. In connection with forgiveness, the importance attached to the event to be forgiven as well as rumination as a predictor for marital forgiveness (34), involving repetitive thinking about negative experiences, may also have a significant impact on the marital relationship. While it has been stated that rumination about negative experiences may lead to a perpetuation of relation problems (18), there are not enough studies about the role of rumination in close relationships, leaving a void to be filled regarding Turkish culture as well as the general literature. In addition, findings regarding gender differences in psychological symptoms and marital adjustment are inconsistent (35-39,40-42).

Eventually, in addition to forgiveness and rumination being connected with physical and mental health and life satisfaction, the marital relation, too, being one of our most important interpersonal relations, correlates with our mental health. Happiness developing in a welladjusted marriage is known to contribute to the partners' mental health in important ways (32). In sum, the aim of this study is to examine the power of the variables forgiveness, importance attached to the incident to be forgiven, and repetitive thinking to explain psychological symptoms and marital adjustment in Turkey and to investigate a possible gender difference in these variables. Accordingly, we expect these variables to predict psychological symptoms and marital adjustment.

\section{METHOD}

\section{Procedure}

After obtaining approval from the ethics committee of Ankara University, the instruments were administered by the researcher, using different sets changing the order of the scales in order to reduce the sequence effect, while the demographic data form remained on the first page for all participants. The participants were volunteers and provided their consent, receiving the necessary information about the study; the forms were handed out in a sealed envelope.

The study sample consisted of 157 married volunteers, 86 female (54.8\%) and 71 male (45.2\%). Data collection started mainly among married volunteers at the researcher's workplace; the sample was expanded using the snowball method. Participants were in the age range 23-58 years $($ Mean $=38.29, S D=38)$; $31.2 \%$ were 35 years and below, $68.8 \%$ above the age of 35. As a duration of marriage not below 1 year was an inclusion criterion, participants had been married for between 2 and 40 years (Mean=12.58, $\mathrm{SD}=12)$. The distribution consisted of $26.1 \%$ having been married for 2-5 years, $19.8 \%$ for $6-10$ years, $22.9 \%$ for $11-15$ years and the remaining $31.2 \%$ for more than 15 years. Of the participants, $26.1 \%$ were high school graduates and $40.1 \%$ university graduates, while the remaining part consisted of literate only, primary or middle school graduates, and persons who had completed a postgraduate degree. Of the participants, $54.8 \%$ was in the middle-income group and $36.3 \%$ in the higher income group. Persons from the low and very highincome group made up the remaining fraction to a lower proportion. The great majority of the participants (81.5\%) were employed. Again, $81.5 \%$ of the participants had children: $33.1 \%$ had 1 child, $40.8 \% 2$ children, and the remaining in this group had 3 or more children.

\section{Measures}

Demographic Data Form: The participants were administered a demographic data form developed by the researcher to record their sociodemographic characteristics, including age, sex, level of education, income level, employment status, duration of marriage, and information about the existence of children.

Importance Attached to the Incident to be Forgiven Scale (IAIFF): This form, prepared by the 
researchers, consists of 9 items listing certain potential situations that might create problems in the marital relationship (like violence, infidelity, or financial matters). Participants were asked which of those incidents they had experienced and how significant these incidents had been. The internal consistency coefficient for the IAIFF in our study was found to be $0.86(\mathrm{n}=157)$.

Forgiving Personality Scale (FP): Developed by Kamat et al. (33), the FP consists of 5 dimensions (pessimistic negativism, virtue of forgiveness, holding a grudge, perceived limits of forgiveness, revenge). In the Turkish validity and reliability study for the scale, one item was excluded from the scale as a result of itemtotal correlations. Calculated with 32 items accordingly, the internal consistency coefficient of the scale was 0.90 and the split-half reliability 0.88 (43). For our study sample, the internal consistency coefficient was calculated to be 0.93 .

Repetitive Thinking Questionnaire (RTQ): Developed by McEvoy et al. (44), the RTQ assesses individuals' tendency toward repetitive thinking about negative life events and solicits answers from persons remembering a distressing event. Turkish validity and reliability studies for the scale were undertaken by Gulum and Dag (45); they calculated an internal consistency coefficient of 0.94 . In the present study, the internal consistency coefficient was 0.95 .

Marital Adjustment Test (MAT): This is a 15 -item scale developed by Locke and Wallace (46). A validity and reliability study for the scale in Turkish was carried out by Tutarel-Kislak (3). The MAT includes one general adjustment question, 8 questions assessing potential areas of agreement, and 6 questions measuring attachment and communication. The internal consistency coefficient of the scale was 0.90 , split-half reliability 0.84 , and test-retest reliability 0.57 . In the current study, the internal consistency coefficient was 0.92 .

Brief Symptom Inventory (BSI): Derogatis (47) developed a 53-item self-report inventory for psychopathological assessment. In the adaptation of the BSI to Turkish, 5 subdimensions were found (anxiety, depression, negative self-concept, somatization, and hostility) (48). The internal consistency coefficient for the whole scale was 0.94 . In our study, we found an internal consistency coefficient of 0.98 .

Data analysis: Before starting the analyses, the researcher removed incomplete forms; the data of 159 participants were controlled for correct input and the distribution of the variables was tested for conformity with the assumptions of multiple-factor analysis. For the study variables, outlier assumptions were evaluated, and after excluding two participants, the analysis was continued using 157 participants. The data obtained in the study were analyzed using SPSS 15.0. Correlations between the study variables were calculated with Pearson product-moment correlation analysis, and the power of the variables forgiveness, importance attached to the incident to be forgiven, and repetitive thinking to predict psychological symptoms and marital adjustment was determined using hierarchical regression analysis. In order to establish gender differences, one-way MANOVA was carried out.

\section{RESULTS}

\section{Analyses relating to variables predicting mental health}

To evaluate variables predicting mental health, a hierarchical regression model was built with the parameters for which correlation analysis had found significant relations. The relations between these variables, as shown in Table 1 , were assessed with Pearson product-moment correlation analysis.

The total BSI score was used as the dependent variable; predictors were ordered according to the strength of the correlation between study variables and BSI. The variable "sex" fell within in the first block of the equation in order to control for the effect of sex, while the total scores of RTQ, FP, and IAIFF were added, in this order, in the second block.

\section{Table 1: Correlations between study variables}

\begin{tabular}{lccccc} 
& MAT & FP & RTQ & IAIFF & BSI \\
\hline MAT & 1 & & & & \\
FP & $0.59^{* *}$ & 1 & & & \\
RTQ & $-0.54^{* *}$ & $-0.54^{* *}$ & 1 & 1 & 1 \\
IAIFF & $-0.31^{* *}$ & $-0.29^{* *}$ & $0.48^{* *}$ & $0.47^{* *}$ & 1 \\
BSI & $-0.50^{* *}$ & $-0.63^{* *}$ & $0.67^{* *}$ & \\
\hline
\end{tabular}

**p<0.01, MAT: Marital Adjustment Test, FP: Forgiving Personality Scale, RTQ: Repetitive Thinking Questionnaire, IAIFF: Importance Attached to the Incident to be Forgiven Scale, BSI: Brief Symptom Inventory 
Table 2: Results of hierarchical regression analysis for variables predicting mental health

\begin{tabular}{lcccccc} 
Predictor variables & $\mathbf{B}$ & $\boldsymbol{\beta}$ & $\mathbf{R}^{2}$ values & Adapted $\mathbf{R}^{\mathbf{2}}$ & Standard error & $\mathbf{F}_{\text {change }}$ \\
\hline Sex & -24.9 & -0.30 & 0.09 & 0.08 & 6.26 & $15.79^{*}$ \\
RTQ & 0.98 & 0.64 & 0.47 & 0.47 & 0.09 & $113.91^{*}$ \\
FP & -0.76 & -0.38 & 0.58 & 0.57 & 0.12 & $37.22^{*}$ \\
IAIFF & 0.68 & 0.14 & 0.59 & 0.58 & 0.28 & $6.00^{*}$ \\
\hline
\end{tabular}

${ }^{*} \mathrm{p}<0.05$, RTQ: Repetitive Thinking Questionnaire, FP: Forgiving Personality Scale, IAIFF: Importance Attached to the Incident to be Forgiven Scale

Table 3: Results of hierarchical regression analysis for variables predicting marital adjustment

\begin{tabular}{lcccccc} 
Predictor variables & B & B & $\mathbf{R}^{\mathbf{2}}$ values & Adapted $\mathbf{R}^{\mathbf{2}}$ & Standard error & $\mathbf{F}_{\text {change }}$ \\
\hline Sex & 5.32 & 0.25 & 0.06 & 0.05 & 1.64 & $10.51^{*}$ \\
FP & 0.29 & 0.56 & 0.38 & 0.37 & 0.03 & $78.79^{*}$ \\
RTQ & -0.11 & -0.28 & 0.43 & 0.42 & 0.02 & $15.37^{*}$ \\
\hline
\end{tabular}

${ }^{*} \mathrm{p}<0.05$, FP: Forgiving Personality Scale, RTQ: Repetitive Thinking Questionnaire

Table 4: Results of variance analysis for sex differences

\begin{tabular}{|c|c|c|c|c|c|c|c|c|c|c|}
\hline \multirow[b]{2}{*}{$\begin{array}{l}\text { Independent } \\
\text { variable }\end{array}$} & \multirow[b]{2}{*}{$\begin{array}{c}\text { Dependent } \\
\text { variable }\end{array}$} & \multicolumn{2}{|c|}{ Women } & \multicolumn{2}{|c|}{ Men } & \multicolumn{2}{|c|}{ Total } & \multirow[b]{2}{*}{$\mathbf{F}$} & \multirow[b]{2}{*}{$\mathbf{p}$} & \multirow[b]{2}{*}{$\eta^{2}$} \\
\hline & & Mean & SD & Mean & SD & Mean & SD & & & \\
\hline \multirow[t]{5}{*}{ Sex } & RTQ & 88.61 & 28.74 & 75.24 & 21.72 & 82.61 & 26.56 & $10.27^{*}$ & 0.002 & 0.06 \\
\hline & FP & 110.39 & 22.26 & 116.31 & 17.14 & 113.07 & 20.26 & 3.37 & 0.068 & 0.02 \\
\hline & MAT & 39.28 & 10.81 & 44.61 & 9.51 & 41.69 & 10.55 & $10.51^{*}$ & 0.001 & 0.06 \\
\hline & BSI & 47.22 & 48.41 & 22.31 & 23.17 & 35.96 & 40.89 & $15.79^{*}$ & $<0.001$ & 0.09 \\
\hline & IAIFF & 10.55 & 10.12 & 5.46 & 5.67 & 8.25 & 8.76 & $14.25^{*}$ & $<0.001$ & 0.08 \\
\hline
\end{tabular}

${ }^{*} p<0.05$, RTQ: Repetitive Thinking Questionnaire, FP: Forgiving Personality Scale, MAT: Marital Adjustment Test, BSI: Brief Symptom Inventory,

IAIFF: Importance Attached to the Incident to be Forgiven Scale

As seen in Table 2, the variance explained by the variable "sex" is $8.0 \%\left(\mathrm{~F}_{\text {change }}[1,155]=15.79 ; \mathrm{p}<0.05\right)$. After "sex," "repetitive thinking" was entered, and with a contribution of $39 \%$, it explained $47.0 \%$ of the variance regarding the psychological symptom score $\left(\mathrm{F}_{\text {change }}[1\right.$, $154]=113.91 ; \mathrm{p}<0.05)$. Subsequently, "forgiving personality" was included in the equation, and the total variance explained by these variables increased to $57.0 \%$ $\left(\mathrm{F}_{\text {change }}[1,153]=37.22 ; \mathrm{p}<0.05\right)$. Finally, after entering the variable "importance attached to the incident to be forgiven" to the equation, the variance explained reached $58.0 \%\left(\mathrm{~F}_{\text {change }}[1,152]=6.0 ; \mathrm{p}<0.05\right)$.

\section{Analyses regarding the variables predicting marital adjustment}

To assess the variables predicting marital adjustment, a hierarchical regression model was built with the parameters found to be significant in the correlation analysis. The relations between these variables, as shown in Table 1, were assessed using the Pearson productmoment correlation technique. The total MAT score was used as the dependent variable; predictors were ordered according to the strength of the correlation between study variables and MAT. The variable "sex" fell within in the first block of the equation in order to control for the effect of sex, while the total scores of FP, RTQ, and IAIFF were added, in this order, in the second block.

As seen in Table 3, the variance explained by the variable "sex" is $5.0 \%\left(\mathrm{~F}_{\text {change }}[1,155]=10.51 ; \mathrm{p}<0.05\right)$. When "forgiving personality" was entered into the equation, together with "sex" it explained $37.0 \%$ of the variance $\left(\mathrm{F}_{\text {change }}[1,154]=78.79 ; \mathrm{p}<0.05\right)$. Therefore, the trait "forgiving personality" contributed $32.0 \%$ to the total variance regarding psychological symptoms. Finally, after entering the variable "repetitive thinking" to the equation, the variance explained increased to $42.0 \%\left(\mathrm{~F}_{\text {change }}[1,153]=15.37 ; \mathrm{p}<0.05\right)$.

\section{Sex differences regarding the study variables}

In order to examine possible sex differences for MAT, BSI, RTQ, FP, and IAIFF variables found in the study, one-way MANOVA was performed. The Box's test result obtained by one-way MANOVA was significant 
(Box's $\mathrm{M}=111.95 ; \mathrm{F}=7.2 ; \mathrm{p}<0.05)$ and the basic assumption of variance-covariance equality was seen to be rejected. The basic effect of the variable "sex" on FP, RTQ, MAT, BSI, and IAIFF scores (Wilks' Lambda $=0.857$ $\mathrm{F}(5,151)=5.02 ; \mathrm{p}<0.05 ; \eta 2=0.14)$ was found to be significant. This result demonstrates that at least one of the scores for RTQ, FP, MAT, BSI, and IAIFF was significantly different for female or male participants. As the MANOVA result found a significant $F$ value regarding the basic effect of sex, the results of variance analysis were evaluated.

According to the results of variance analysis presented in Table 4, sex differences regarding marital adjustment were significant $\left(\mathrm{F}=10.51 ; \mathrm{p}<0.05 ; \eta^{2}=0.06\right)$; marital adjustment scores for women (Mean $=39.28$; $\mathrm{SD}=10.81)$ were lower than those for men (Mean $=44.61$; $S D=9.51)$. Sex differences were also significant regarding psychological symptoms $(\mathrm{F}=15.79 ; \mathrm{p}<0.05$; $\left.\eta^{2}=0.09\right)$ : BSI scores for women $($ Mean $=47.22$; $\mathrm{SD}=48.41)$ were higher than those for men (Mean=22.31; $S D=23.17$ ). Furthermore, sex differences were significant regarding repetitive thinking scores $\left(\mathrm{F}=10.27 ; \mathrm{p}<0.05 ; \eta^{2}=0.06\right)$ : Women's scores for the level of repetitive thinking (Mean=88.61; $\mathrm{SD}=28.74)$ were higher than those in men (Mean=75.34; $\mathrm{SD}=21.72$ ). However, for the characteristic of "forgiving personality," no significant difference was found between women and men $\left(F=3.37, p>0.05 ; \eta^{2}=0.02\right)$. Finally, significant sex differences were found for "importance attached to the incident to be forgiven" ( $\left.F=14.25 ; \mathrm{p}<0.05 ; \eta^{2}=0.08\right)$; women's scores $(M e a n=10.55 ; \mathrm{SD}=10.12)$ were higher than men's (Mean=5.46; $\mathrm{SD}=5.67)$.

\section{DISCUSSION}

This study found that the variables predicting psychological symptoms are sex, repetitive thinking, forgiving personality, and importance attached to the incident to be forgiven. In the literature, there are studies emphasizing sex differences regarding psychological symptoms (35-37) as well as findings rejecting sex differences (38-40). Our study indicates that male sex is negatively and female sex positively related with psychological symptoms. However, the fact that the BSI is a general instrument for psychopathological assessment may be the reason why the predictive power of sex appeared to be low. The conflicting results may suggest that the role of sex in psychological symptoms is not sufficiently clear.

However, in line with the findings of numerous studies the level of repetitive thinking explains psychological symptoms (19-22,25). One study in Turkey also found that repetitive thinking about negative contents predicted depressive symptoms (26). In the response style model, the proposed negative effects of rumination on mental health are explained with the affected individuals' drawing negative conclusions from their experiences, developing a more pessimistic outlook, losing their problem-solving skills, experiencing relationship problems, and trying less hard to get away from the negative experience (19). In addition, considering that many of the studies of rumination are rather focusing on depression and anxiety rather than general psychological symptoms, we believe that our findings are useful in the context of the literature. The finding of our study that, after the variables of sex and repetitive thinking, a forgiving personality explains psychological symptoms supports other studies that found a negative correlation between forgiveness and psychological symptoms $(9,10,12,15,24,32)$ and the power of a tendency towards a forgiving personality to predict mental health (32). Even though there is one finding that did not find a correlation between forgiveness and mental health (40), results generally indicate that a person who has been offended can avoid negative emotions by way of forgiveness, thus reaching psychological maturity (49). As forgiving personality is thought to be important in explaining and understanding the protective and remedial factors in mental health, it should be recommended to increase the number of studies related to this issue. While the explanatory power of the last variable predicting psychological symptoms in our study, "importance attached to the incident to be forgiven," was found to be low, we may well emphasize that the importance given to a negative experience can affect people more adversely, increasing stress, potentially trapping them in a repetitive short circuit, and thus being detrimental to their mental health.

Another finding related to the research question regards the predictive power of the variables sex, forgiving personality, and repetitive thinking for marital adjustment. The analysis indicates that on average men achieve higher marital adjustment scores than women, which is in line with some findings in the literature $(36,37,42)$. The finding that sex is a low-level predictor for marital adjustment is consistent with some studies (41); however, it is interesting to note that other studies could establish no significant difference in marital adjustment according to sex $(38,39,42)$.

Forgiving personality is another prominent variable in marital adjustment, and the international literature 
stresses the positive contributions of forgiveness to the marital relationship, while in the Turkish literature, the assessment of forgiveness in the marital relationship is still relatively recent. In parallel with the results of our study, a significant positive correlation between forgiveness and marital adjustment and an increase of marital adjustment with a rising level of forgiveness have been stated $(9,10,30-32,34)$. There are also findings indicating that adjustment predicts forgiveness $(30,34,35)$ and forgiveness predicts relationship quality and satisfaction $(32,33)$. This relation between marital adjustment and forgiveness has been explained with the fact that in close relationships, couples are more willing to forgive and continue their relation and couples with a high relationship quality have a greater tendency to overlook hurtful experiences or reduce their effects. A couple's interests in the relationships overlap, the shared past facilitates establishing empathy, and in welladjusted relationships, the offending partner can more easily convey apologies and regrets to the other party (18). Forgiveness overcomes distance in close relationships, thus causing a lesser burden both individually and in the relationship (30); it remediates resentment, allows restoring lost trust, and thus has a positive effect on the relationship (17). There are studies showing the attributions of responsibility related to negative events experienced in married life to be correlated with marital adjustment (50), being a predictor of forgiveness $(30,35)$. In this context, it is seen that attributions made regarding negative events in marriage affect both marital adjustment and forgiveness. Seen as a positive personality trait, forgiveness allows overcoming problems experienced in a marriage and contributes to marital adjustment. In general, while the number of studies treating forgiveness in marital relationship increases, it still seems necessary to broaden the studies on this issue in the Turkish literature. We may also say that the use of the correlation between forgiveness and marital adjustment in clinical interventions will be operational. The last variable established to predict marital adjustment was repetitive thinking. The literature states that with rising levels of repetitive thinking about negative events, marital adjustment decreases $(18,31,34)$. Repeatedly thinking about negative experiences increases negative mood and prevents forgetting the event over time, which is assumed to have an adverse effect on marital adjustment. For Turkish culture, more studies about this topic are needed.

Examining the joint variables predicting both mental health and marital adjustment, we can say that the explanatory level of sex for these variables is low, while the effect of repetitive thinking and forgiving personality on the dependent variables is greater. Related to theoretical explanations, the power of repetitive thinking to explain mental health becomes prominent. Drawing negative conclusions from adverse experiences, pessimistic thought and being trapped in such a loop is understood, in keeping with the literature, as being severely detrimental to mental health (19). Marital adjustment, however, is explained to a greater degree by forgiving personality. It is known that positive attributions made to the spouse's characteristics increase marital adjustment (50). Evidently, a person's intrinsic forgiveness similarly contributes to marital adjustment. Such a personality trait, defined as being forgiving, may erase the traces of negative experiences (30) and increase the quality of the relationship. Thus, when a person does not give too much room to repetitive thinking, we can say that the forgiveness process in the interpersonal relation has been activated (18).

Our study also investigated the correlation between marital adjustment and psychological symptoms; in line with the literature (32), with lower marital adjustment, an increase in psychological symptoms was observed, and a better-adapted marriage was found to be related with better mental health. Marriage is one of our most important interpersonal relations and occupies a large part of our lives. Therefore, persons experiencing marital problems or failing marriages often develop psychological symptoms and seek help (3). By contrast, the better state of mental health correlated with a welladapted marriage may derive from the benefits of intimacy, love, and support found in marriage. Finally, we think that the correlation between marital problems and mental health are clinically relevant, as they may affect the onset, continuation, and aggravation of mental problems.

According to our results, assessing sex differences regarding the study variables, we have seen that women's marital adjustment is lower, which is in keeping with some findings in the literature $(36,37,42)$ though contradicted by others (39). The Turkish validity and reliability study for the MAT, which was also used in our study, did not find a significant difference in participants' marital adjustment according to sex (3). However, when assessing the regression and MANOVA analyses made in our study jointly, we can point out that a correlation between sex and marital adjustment emerges consistently. Equally, when looking at psychological symptoms we can see that these are found more commonly in women, and the findings regarding 
sex differences are consistent with the literature (51-53). The fact that women report more symptoms than men in these studies may be explained by a greater social acceptance for women to communicate their problems, making them more open to sharing their issues. Some interpretations in the literature suggest that the marriage experience affects women more negatively (53); due to gender discrimination, women are expected to mature sooner, and for this reason they express their feelings, making them more vulnerable to contracting psychological disorders (52). In addition, we should not forget that in married life, pressure put on women, the use of force by men against women, and a tendency to violence can pose problems for psychological health (54-56). It is said that women exposed to various types of violence may not find support and use coping mechanisms such as self-incrimination and conflict experience, which might increase psychological symptoms (56). It seems to be important to evaluate sex, a relevant variable both sociologically and biologically, in its impact on mental health and to assess it as a risk factor.

While there are not sufficient studies showing women mentally repeating or ruminating more on negative experiences, there are some that support $(21,26,57)$ and others that contradict this finding $(10,58)$. It has been said that the reason for women to think more repetitively after a negative situation could be that they have a stronger feeling of not being able to control their feelings and events while perceiving greater responsibility in the relationship (57). We should not forget, though, that this sensation and perception is not solely related with the woman but rather connected with the roles society attributes to women and men; therefore, a multidirectional investigation of this issue is an important contribution to the field. In this sense, our study contributes to filling a gap in the literature.

The absence of a sex difference in forgiving personality is consistent with most findings in the literature $(10,14,35,40)$. Studies addressing this topic show that a general judgment about sexual differences regarding forgiveness cannot be reached. Finally, the situation that women attach more importance to negative experiences or events to be forgiven compared to men may also be explained by their greater regard for the negative experiences as an effect of women's gender roles, which include the expectation that they be more emotional, attentive to detail, and more relationshipcentered.

Finally, this study emphasizes-as proposed in the Social-Psychological Determinants Model of
Forgiveness-that one of the factors directly affecting the forgiveness process is rumination; in married persons, forgiveness and at the same time avoiding to think about negative experiences repeatedly have a positive impact on marital adjustment and mental health. In marital therapy interventions, the spouses should be encouraged to work with mutual forgiveness, and attention should be given, as the response style model points out, to liberate the person from the negative thinking loop and develop their problem-solving skills. In view of general psychological symptoms, evidently forgiveness needs to be taken into account both as a risk factor and a protective factor. It is clear that interventions aimed at reaching, stabilizing, and increasing a satisfying, happy, well-adapted marital relation will make important contributions to the psychological health of the couple individually and jointly. For clinically working professionals, when trying to find the most suitable intervention in the psychotherapy process for the specific case, it will be useful to consider that, as shown in this study, the variables sex, forgiveness trait, and repetitive thinking are all equally involved in the psychological health of married persons and the adjustment of their intimate relationship.

A few limitations that might affect the findings of this study need to be mentioned. Firstly, the study sample consisted mostly of married individuals living in Ankara. Secondly, the instruments used being selfreport scales involves the risk of various biases. Furthermore, the great majority of the participants were of a high education level, and relatively few persons from a low socio-economic level were included in the sample. These factors may limit the generalizability of the study. To avoid this limitation, future studies should be carried out on broader samples with a more even socio-economic distribution from different regions. In addition, the study design is not suited to establish cause-and-effect relations between the variables. Future studies might use different techniques, such as interviews and quasi-experimental or longitudinal approaches.

\begin{tabular}{|l|l|l|}
\hline \multicolumn{4}{|l|}{ Contribution Categories } & Author Initials \\
\hline \multirow{3}{*}{ Category 1} & Concept/Design & I.G.G., S.T.K. \\
\cline { 2 - 3 } & Data acquisition & I.G.G. \\
\cline { 2 - 3 } & Data analysis/Interpretation & I.G.G., S.T.K. \\
\hline \multirow{3}{*}{ Category 2} & Drafting manuscript & I.G.G., S.T.K. \\
\cline { 2 - 3 } & Critical revision of manuscript & S.T.K. \\
\hline \multirow{2}{*}{ Category 3} & Final approval and accountability & S.T.K. \\
\hline \multirow{2}{*}{ Other } & Technical or material support & I.G.G. \\
\cline { 2 - 3 } & Supervision & S.T.K. \\
\hline
\end{tabular}


Ethics Committee Approval: This study was approved from the ethics committee of Ankara University.

Informed Consent: Written informed consent was obtained from the patients.

Peer-review: Externally peer-reviewed.

Conflict of Interest: The authors declare no conflict of interest.

Financial Disclosure: The authors declare no financial support.

\section{REFERENCES}

1. Ozguven GE. Marriage and Family Therapy. First ed. Ankara: PDREM Yayinlari, 2000. (Turkish)

2. Kilinc E. Family Therapies: In Koroglu E, Turkcapar H (editors). Methods of Psychotherapy: Theories and Instructions for Application. Ankara: Hekimler Yayin Birligi, 2009, 229-271. (Turkish)

3. Tutarel-Kislak S. Reliability and validity of the Marital Adjustment Test (MAT). Psikiyatri Psikoloji Psikofarmakoloji (3P) Dergisi 1999; 7:50-57. (Turkish)

4. Erbek E, Bestepe E, Akar H, Eradamlar, N, Alpkan RL. Marital adjustment. Dusunen Adam The Journal of Psychiatry and Neurological Sciences 2005; 18:39-47. (Turkish)

5. Erdogan S. A Study of the Relations Between Marital Adjustment and Psychiatric Disorders, Attachment Styles, and Temperament and Personality Traits. Specialization Thesis, Gazi University, Medical Faculty, Department of Psychiatry, Ankara, 2007. (Turkish)

6. Demiray O. A Study of Marital Adjustment According to Demographic Characteristics. Master's Thesis, Dicle University Institute of Social Sciences, Diyarbakır, 2006. (Turkish)

7. Idiz Z. A Sociopsychological Study of the Relations Between Marital Adjustment, Marital Investment, Domestic Violence, and Suicide Attempts. Master's Thesis, Ankara University, Institute of Social Sciences, Ankara, 2009. (Turkish)

8. Sardogan ME, Karahan TF. The effect of human relation skill training program for married couples on the level of marital adjustment of married couples. Ankara University Journal of Faculty of Educational Sciences 2005; 38:89-102. (Turkish)

9. Fincham F, Beach SRH. Forgiveness and marital quality: precursor or consequence in well-established relationships? J Posit Psychol 2007; 2:260-268.[CrossRef]

10. McNulty JK. Forgiveness in marriage: putting the benefits into context. J Fam Psychol 2008; 22:171-175. [CrossRef]

11. Enright RD. Counseling within the forgiveness triad: on forgiving, receiving, forgiveness and self-forgiveness. Couns Values 1996; 40:107-126. [CrossRef]

12. Allemand M, Hill PL, Ghaemmaghami P, Martin M. Forgivingness and subjective well-being in adulthood: the moderating role of future time perspective. J Res Pers 2012; 46:32-39. [CrossRef]

13. McCullough ME. Forgiveness as human strength: theory, measurement, and links to well-being. J Soc Clin Psychol 2000; 19:43-55. [CrossRef]
14. Toussaint L, Webb JR. Gender differences in the relationship between empathy and forgiveness. J Soc Psychol 2005; 145:673685. [CrossRef]

15. Berry JW, Worthington EL Jr, O'Connor LE, Parrott L, Wade NG. Forgivingness, vengeful rumination, and affective traits. J Pers 2005; 73:183-225. [CrossRef]

16. Enright RD, The Human Development Study Group. The moral development of forgiveness: In Kurtines WM, Gewirtz JL (editors). Handbook of Moral Behavior and Development, Hillsdale, NJ: Lawrence Erlbaum, 1991, 1:123-152.

17. Sells JN, Hargrave TD. Forgiveness: a review of the theoretical and empirical literature. J Fam Ther 1998; 20:21-36. [CrossRef]

18. McCullough ME, Rachal KC, Sandage SJ, Worthington EL, Brown SW, Hight TL. Interpersonal forgiving in close relationships: II. Theoretical elaboration and measurement. J Pers Soc Psychol 1998; 75:1586-1603. [CrossRef]

19. Nolen-Hoeksema S. Responses to depression and their effects on the duration of depressive episodes. J Abnorm Psychol 1991; 100:569-582. [CrossRef]

20. Conway M, Csank PA, Holm SL, Blake CK. On assessing individual differences in rumination on sadness. J Pers Assess 2000; 75:404-425. [CrossRef]

21. Treynor W, Gonzalez R, Nolen-Hoeksema S. Rumination reconsidered: a psychometric analysis. Cognit Ther Res 2003; 27:247-259. [CrossRef]

22. Burwell RA, Shirk SR. Subtypes of rumination in adolescence: Associations between brooding, reflection, depressive symptoms, and coping. J Clin Child Adolesc Psychol 2007; 36:56-65. [CrossRef]

23. Wells A. A multi-dimensional measure of worry: development and preliminary validation of the anxious thought inventory. Anxiety Stress Coping 1994; 6:289-299. [CrossRef]

24. Segerstrom SC, Roach AR, Evans DR, Schipper LJ, Darville AK. The structure and health correlates of trait repetitive thought in older adults. Psychol Aging 2010; 25:505-515. [CrossRef]

25. Nolan SA, Roberts JE, Gotlib IH. Neuroticism and ruminative response style as predictors of change in depressive symptomatology. Cognit Ther Res 1998; 22:445-455. [CrossRef]

26. Neziroglu G. An investigation on the relationship between rumination, experiential avoidance and problem solving skills in relation to depressive symptoms. Master's Thesis, Hacettepe University, Ankara, 2010. (Turkish)

27. Nolen-Hoeksema S, Harrell ZA. Rumination, depression, and alcohol use: tests of gender differences. J Cogn Psychother 2002; 16:391-403. [CrossRef]

28. Hilt LM, Cha CB, Nolen-Hoeksema S. Nonsuicidal self-injury in young adolescent girls: moderators of the distress-function relationship. J Consult Clin Psychol 2008; 76:63-71. [CrossRef]

29. Cooper ML, Russell M, Skinner JB, Frone MR, Mudar P. Stress and alcohol use: moderating effects of gender, coping, and alcohol expectancies. J Abnorm Psychol 1992; 101:139-152.

30. Fincham FD. The kiss of the porcupines: from attributing responsibility to forgiving. Pers Relatsh 2000; 7:1-23. [CrossRef] 
31. Kachadourian LK, Fincham F, Davila J. Attitudinal ambivalence, rumination, and forgiveness of partner transgressions in marriage. Pers Soc Psychol Bull 2005; 31:334-342. [CrossRef]

32. Berry JW, Worthington Jr. EL. Forgiveness, relationship quality, stress while imagining relaitonship events, and physical and mental health. J Couns Psychol 2001; 48:447-455. [CrossRef]

33. Kamat VI, Jones WH, Row KL. Assessing forgiveness as a dimension of personality. Individ Differ Res 2006; 4:322-330.

34. Paleari FG, Regalia C, Fincham F. Marital quality, forgiveness, empathy, and rumination: a longitudinal analysis. Pers Soc Psychol Bull 2005; 31:368-378. [CrossRef]

35. Taysi E. Forgiveness in Dyadic Relationships: The Role of Relationship Quality and Attributions. Doctoral Thesis, Ankara Universitesi, Ankara, 2007. (Turkish)

36. Orathinkal J, Vansteenwegen A. Do demographics affect marital satisfaction? J Sex Marital Ther 2007; 33:73-85. [CrossRef]

37. Duman-Temel E. Mediating role of marital satisfaction in the types of infidelity-forgiveness, trait positive affect-forgiveness and coping-forgiveness relationships in married men and women. Master's Thesis, Middle East Technical University, Ankara, 2013.

38. Celik M. Study for the Development of a Marital Satisfaction Scale. Doctoral Thesis, Cukurova University, Adana, 2006. (Turkish)

39. AcikO. Relation Between Marital Satisfaction and Attachment Styles. Master's Thesis, Ege University, Izmir, 2008. (Turkish)

40. Macaskill A. Differentiating dispositional self-forgiveness from other-forgiveness: associations with mental health and life satisfaction. J Soc Clin Psychol 2012; 31:28-50. [CrossRef]

41. Cihan-Gungor H. Developing a Model to Explain Marital Satisfaction. Doctoral Thesis, Gazi University, Ankara, 2007. (Turkish)

42. Cag P, Yildirim I. Relational and personal predictors of marital satisfaction. Turk Psikolojik Danisma ve Rehberlik Dergisi 2013; 4:13-23. (Turkish)

43. Soylu B. Investigation of the Differences between the concepts of psychological and social exclusion and social rejection on the basis of aggression: sexuality, forgiving personality, and the role of negative affect. Hacettepe University, Ankara, 2010.

44. McEvoy PM, Mahoney AEJ, Moulds ML. Are worry, rumination, and post-event processing one and the same? Development of the repetitive thinking questionnaire. J Anxiety Disord 2010; 24:509519. [CrossRef]

45. Gulum V, Dag I. The Turkish adaptation, validity and reliability study of the Repetitive Thinking Questionnaire and the Cognitive
Flexibility Inventory. Anadolu Psikiyatri Derg 2012; 13:216-223. (Turkish)

46. Locke HJ, Wallace KM. Short marital-adjustment and prediction tests: their reliability and validity. Marriage Fam Living 1959; 21:251-255. [CrossRef]

47. Derogatis LR. Brief Symptom Inventory (BSI) Administration, Scoring and Procedures Manual-II. Baltimore MD: Clinical Psychometric Research, 1992.

48. Sahin NH, Durak A. Brief Symptom Inventory-BSI: Adaptation for Turkish young people. Turk Psikoloji Dergisi 1994; 9:44-56. (Turkish)

49. McCullough ME, Worthington EL. Models of interpersonal forgiveness and their applications to counseling: review and critique. Couns Values 1994; 39:2-14. [CrossRef]

50. Tutarel-Kislak S. Relation of Marital Adjustment with Causality and Responsibility Attributions. Turk Psikoloji Dergisi 1997; 12:55-64. (Turkish)

51. Oyekcin DG. Sociodemographic features and psychiatric diagnosis of the patients who referred to an East Anatolian city hospital's psychiatry polyclinic during one year period. Anadolu Psikiyatri Derg 2008; 9:39-43. (Turkish)

52. Cetin-Dagli S. Evaluation of the Prevalence of Violence among Students at Duzce Vocational High School and the Short Symptom Inventory. Medical Specialization Thesis, Duzce University, Duzce, 2009.

53. Kilic M. Relationship Between the Mental Symptoms Seen in Married Couples and the Family Functionality Level. Master's Thesis, Dokuz Eylul University, Izmir, 2012.

54. Tezcan S, Yavuz S, Tunckanat H. Domestic Violence Against Women and Health Outcomes. Domestic Violence Against Women in Turkey. Hacettepe University Institute for Population Studies, Ankara: Elma Teknik Publications, 2009. (Turkish)

55. Damka Z, Tutarel-Kislak S. Women victims of violence: a mental health survey in sheltered homes. Kadin/Women 2000. 2009; 10:1-26.

56. Tuncay-Senlet E. Domestic violence against women in relations to marital adjustment and psychological well-being, with the effects of attachment, marital coping, and social support. Doctoral Thesis, Middle East Technical University, Ankara, 2012.

57. Nolen-Hoeksema S, Jackson B. Mediators of the gender difference in rumination. Psychol Women Q 2011; 25:37-47. [CrossRef]

58. Karatepe HT. Turkish Adaptation, Validity and Reliability of Ruminative Thought Style Questionnaire. Specialization Thesis, Bakirkoy Prof. Dr. Mazhar Osman Training and Research Hospital for Psychiatry and Neurology, Istanbul, 2010. 